First, use only $0.5-1 \mathrm{ml}$ of local anaesthetic to the area of the insertion point, using a 25 gauge $\times 16 \mathrm{~mm}$ (5/8 inch) orange needle. I would avoid the use of a green 21 gauge needle along the proposed track as there are cases of implants having been recorded as palpable after insertion but not palpable a few days later. I surmise that what was palpated was not the implant but the local anaesthetic and the effect of the green needle track. There is no need to anaesthetise the track, and without the volume of local anaesthetic it is easier to visualise the insertion needle as it advances. I also feel there is the danger of numbing the dermis and it is then possible to insert the implant too superficially.

Second, once the needle of the inserter is inserted through the dermis, it should then be withdrawn until the needle's bevel is just seen; only then, and with the inserter needle parallel to the skin, should it be advanced. Use of this technique should substantially reduce the number of impalpable implants.

Martyn Walling, FRCGP, FFSRH

General Practitioner, Boston and Doctor, Kingsley Ward Centre, Southend on Sea, UK; martyn.belmontdoc@sky.com

Competing interests None declared.

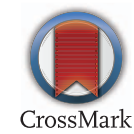

J Fam Plann Reprod Health Care 2016;42:75. doi:10.1136/fprhc-2015-101306

\title{
REFERENCES
}

1 Walling M. How to remove impalpable Implanon ${ }^{\circledR}$ implants. J Fam Plann Reprod Health Care 2005;31:320-321.

2 Mansour D, Walling M, Glenn D, et al. Removal of non-palpable etonogestrel implants. J Fam Plann Reprod Health Care 2008;34:89-91.

\section{Inserting the etonogestrel contraceptive implant}

I have been involved with removing impalpable contraceptive implants for over 15 years and have removed many hundreds of such implants. ${ }^{12}$ I also act as an expert to defend doctors and nurses who have inserted such implants. With this experience I would offer two pieces of advice for those inserting implants. 